\title{
Replenishing Humic Acids in Agricultural Soils
}

\author{
Michael Susic \\ Biogon Pty Ltd., 17b Poole Rd., Glass House Mountains, Queensland 4518, Australia; michael@biogon.com.au; \\ Tel.: +61-754-969-516 \\ Academic Editors: Yusuf Genc and Graham Lyons \\ Received: 23 July 2016; Accepted: 21 September 2016; Published: 28 September 2016
}

\begin{abstract}
For many decades, it was commonly believed that humic acids were formed in soils by the microbial conversion of plant lignins. However, an experiment to test whether these humic acids were formed prior to plant matter reaching the soil was never reported until the late 1980s (and then only as a side issue), even though humic acids were first isolated and reported in 1786. This was a serious omission, and led to a poor understanding of how the humic acid content of soils could be maintained or increased for optimum fertility. In this study, commercial sugar cane mulch and kelp extracts were extracted with alkali and analyzed for humic acid content. Humic acids in the extracts were positively identified by fluorescence spectrophotometry, and this demonstrated that humic acids are formed in senescent plant and algal matter before they reach the soil, where they are then strongly bound to the soil and are also resistant to microbial metabolism. Humic acids are removed from soils by wind and water erosion, and by water leaching, which means that they must be regularly replenished. This study shows that soils can be replenished or fortified with humic acids simply by recycling plant and algal matter, or by adding outside sources of decomposed plant or algal matter such as composts, mulch, peat, and lignite coals.
\end{abstract}

Keywords: humic; acid; soil; senescent; plant; algal; fluorescence; microbial; lignin; compost; mulch; coal

\section{Introduction}

Humic acids are brown-black polymeric acids of plant origin that are ubiquitous at the Earth's surface. The term humus originally meant all organic compounds of plant origin in the soil, and is used as such in this report. The term humic acids is used for the brown-black, polymeric, alkali-soluble acids found in soils, plants, seagrasses, fungi, sediments, and terrestrial and marine waters.

They contribute to soil fertility [1] - a fact that has been recognized since ancient times. Even though humic acids bind strongly to soils [2] and are resistant to microbial metabolism, and therefore have a very long half-life in soils, they are depleted from soils by wind and water erosion, and by water leaching [3]. So, it is important to replenish them to maintain or improve soil fertility. As the study of humic acids progressed from 1786 (when they were first extracted from peat bogs in Germany [4]), their importance has become clearer. Not only are they important for soil fertility, but they are also precursors of kerogens, peat, asphalt, bitumen, petroleum, and coal. They influence the agricultural environment by complexing with metals and organics, which can modify the toxicity of heavy metals, pesticides, and herbicides. 
Within the past 150 years or so, the structures of naturally-occurring organic compounds have generally been elucidated within decades of their discovery. The situation with humic acids has, in contrast, been quite different [5]. Even in the mid-1980s, there was debate on such basic matters as whether humic acids were predominantly aliphatic or aromatic [6]. Since the late 1800s, and especially from the 1920s onwards, it was commonly believed that humic acids were formed by the microbial conversion of plant lignins in the soil.

In 1797, humic acids were extracted from plant matter [7], but there does not appear to be another such report until 1987 [8], when it was done inadvertently. In 1989 [9] and 1991 [2], we reported for the first time that humic acids are present in senescent plant and algal matter, which meant that they enter the soil prior to any supposed conversion of plant lignins by microbes. Similar results have been reported since then [10,11]. More recently [12], humic acids were isolated from maize plants at different stages of maturity, and it was concluded that humic acids originate from the preservation of plant tissue. Humic acids have been sequentially separated and analyzed [13] to obtain better insights into their structure and composition, so that the simplistic models of the past are giving way to more sophisticated models $[13,14]$. In our previous work, the analysis of humic acids in plant matter was reported only as a side issue to the analysis and occurrence of humic acids in the environment, so this study reports a much more thorough and accurate assessment.

Analytical techniques that have been used historically include elemental analysis, UV-Visible spectrophotometry, solid-state IR, and solid-state NMR. These techniques were very imprecise when compared to their results for other organic molecules, so superior techniques have been used $[13,15]$ in more recent times, including fluorescence spectrophotometry (FS). FS is a particularly powerful and convenient technique for the analysis of humic acids because the excitation spectra and emission spectra each occur over an extremely wide range with highly characteristic shapes (ideal for 3-D fluorescence); even more importantly, however, the excitation and emission spectra overlap [15]-a phenomenon that does not appear to occur for other organic compounds. Therefore, this fundamental technique formed the basis of the analytical analysis in this study.

In contrast to the structure of humic acids in soils, most commercially available humic acid products are soluble potassium humates. These soluble salts are readily leached from soils by rainfall and irrigation, and therefore have minimal effect on the long-term humic acid status of soils. This study compares the fluorescence data of humic acids from various sources to that of soil humic acids to determine if such sources are useful for the replenishment of soil humic acids.

\section{Results}

\subsection{Yield of Humic Acids}

The sugar cane mulch used in this study yielded $5.12 \mathrm{~g}$ of purified humic acids (a shiny, black amorphous material, typical of humic acids), which is $1.65 \% w / w$ of the dried mulch. This must be considered a minimum amount, as it appeared that further humic acids could not be extracted because they were tightly bound to plant matter-probably proteins, etc.

Humic acids extracted from soils, a commercial product (Sigma-Aldrich, St. Louis, MO, USA), and kelp were not quantified. However, it was observed that commercial kelp extracts yielded very little material other than humic acids.

\subsection{Identification and Comparison of Humic Acids}

The extracted humic acids were identified and compared by fluorescence spectrophotometry, as shown in Figures 1 and 2. 
Fluoresence of Alkali Soluble Humic Acids from Various Sources

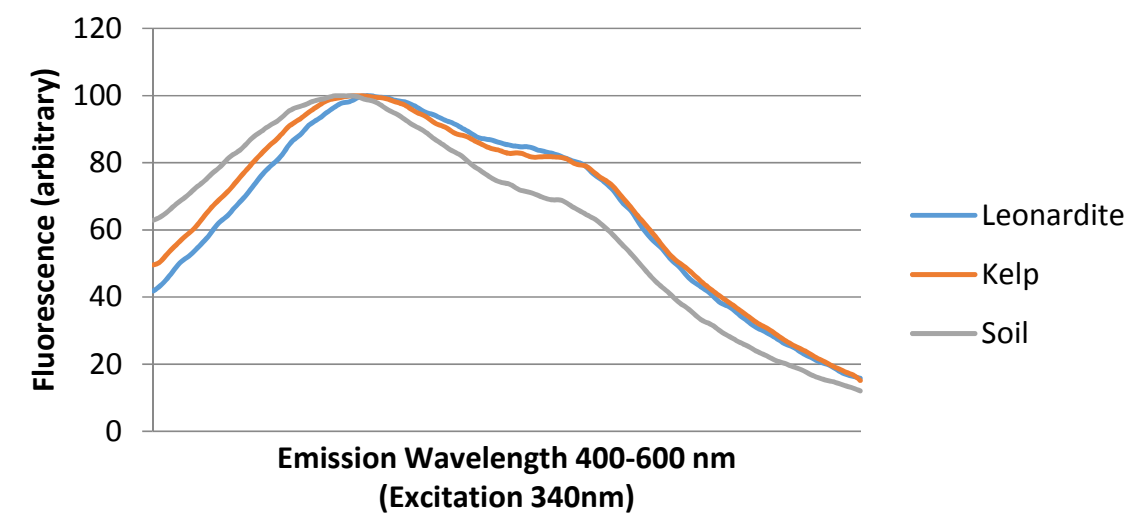

Figure 1. Fluorescence spectra of humic acids extracted from soil, kelp, and a commercial humic acid (sourced from Leonardite coal).

\section{Fluoresence of Humic Acids from Various}

Sources

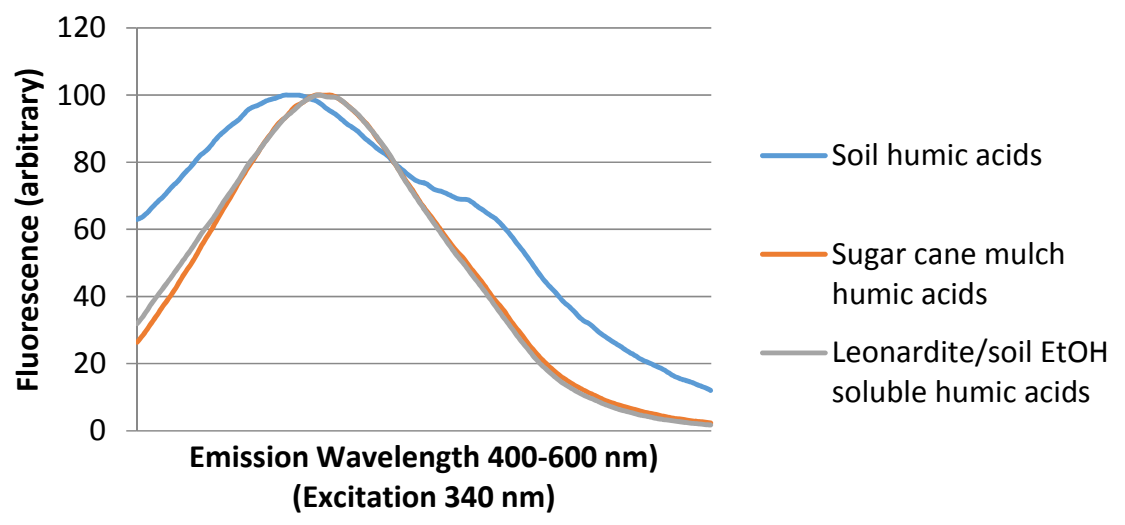

Figure 2. Fluorescence spectra of humic acids extracted from soil, sugar cane mulch, and Leonardite coal (NZ) (Leonardite/soil ethanol-soluble extracts were identical, so only one trace is shown).

\section{Discussion}

Humic acids are readily extracted from many sources with alkali by conventional methods. It has previously been found [16] that the fluorescence spectra of humic acids extracted from different soil types and from soils containing different plant cover (e.g., grasses or trees) were almost identical, showing that all soil humic acids are very similar.

Figure 1 demonstrates that purified humic acids extracted from a commercial humic acid, kelp, and soil are almost identical. This has the following important ramifications:

(i) It has been commonly believed that Leonardite coal humic acids are different from soil-extracted humic acids, and this finding shows that this was incorrect.

(ii) Kelp extracts are mainly humic acids (as potassium humate), and these humic acids are very similar to soil humic acids. As a side issue, kelp extracts are known to promote plant growth, which may be due to hormones rather than their humic acid content [16]. 
(iii) There is a slight difference between the fluorescence spectra of Leonardite coal/kelp humic acids and soil humic acids. This can be explained by a slightly different composition of the suite of humic acids in these samples. This can be explained by differences in the formation of humic acids via the furfural pathway from xylose and fructose (and perhaps ribose and arabinose) in the original plant or algal matter [15].

Figure 2 demonstrates that humic acids are soluble in organic solvents, which was reported as far back as 1957 but has rarely been used since. In this study, it was found that humic acids only dissolve slowly in organic solvents, and have to be left in contact with such solvents for many hours, even days. This unusual characteristic is explained by the humic acid molecules changing their structure slowly [13] to go from a highly water-soluble to a highly organic solvent-soluble structure. This finding can benefit research to better determine humic acid structures and chemistry, since solutions in organic solvents can yield far more information with modern instrumental techniques (e.g., solution IR, NMR, MS, and normal-phase HPLC) than using aqueous solutions. Such knowledge can then give a better understanding of the role and use of humic acids in agriculture.

Figure 2 also shows that the ethanol-soluble humic acids fraction is substantially different from the alkali-soluble fraction. This is again explained by different humic acid components being more soluble in ethanol compared to alkali. In fact, the ethanol-soluble fraction more closely resembles a fulvic acid fluorescence spectrum.

The sugar cane mulch humic acids are almost identical to the ethanol-soluble soil humic acids, which means that sugar-cane mulch contains many (but not all) of the soil humic acid components. In contrast, from Figure 1 it can be seen that kelp contains almost the same humic acid components as soil humic acids.

\section{Experimental}

\subsection{Chemicals and Materials}

Analytical grade chemicals were purchased from Ajax Chemicals, Australia (sodium hydroxide, potassium hydroxide) and Sigma-Aldrich, USA (sulfuric acid, ethanol, and n-butanol). Technical grade humic acid was purchased from Sigma-Aldrich, USA, and purified by a previously reported method [9]. Sugar cane mulch was purchased from a local agricultural supplier, and kelp extract (as the potassium salt) was obtained from WNK group, China. Leonardite coals were obtained from New Zealand (NZ) through personal contacts.

\subsection{Extracting Humic Acids from Senescent Plant and Algal Matter}

Sugar cane mulch $(310 \mathrm{~g})$ was extracted with $1 \mathrm{~L}$ of $0.1 \mathrm{M}$ potassium or sodium hydroxide by allowing the mixture to stand for 2 days with occasional shaking. This procedure was repeated twice until no more humic acid could be extracted, and the solutions were combined (not all of the humic acids could be extracted with alkali, because some seems to bind to proteins or other organic matter). The solution was filtered in small portions through a Whatman no. 40 filter paper, and the filtrate portions were added together (small portions had to be used because fine particles clogged the filter paper). The filtrate was then centrifuged at $2000 \mathrm{rpm}$, and the supernatant was collected. Centrifugation was essential to remove fine particles from the filtrate, because after acidification, humic acids strongly bind to these fine particles. The resulting filtrate was then acidified with $10 \%$ sulfuric acid to a $\mathrm{pH}$ of $\sim 1$, which gave a brown-black precipitate. The precipitate was filtered through a Whatman no. 40 filter paper and air-dried at ambient conditions, then dried further at $110{ }^{\circ} \mathrm{C}$.

Humic acids were extracted from local soils and Leonardite coals as previously described [9]. They were also extracted from commercially available kelp extracts by the same method as described above for the extraction of sugar-cane mulch. Humic acids are slowly soluble in alcohols such as ethanol and n-butanol, and after allowing the extracted humic acids to stand in such solvents for at least $12 \mathrm{~h}$, the solution was decanted and used for further studies. A Perkin Elmer (USA) LS 
45 fluorometer with quartz cuvettes was used to measure fluorescence, with an excitation wavelength of $340 \mathrm{~nm}$ and emission scanning from 400 to $600 \mathrm{~nm}$.

\section{Conclusions}

The analysis of humic acids from various sources has shown that they are very similar to those occurring in soils, which is consistent with more modern research [12]. This means that these sources can be used to complement or replenish soil humic acid levels. Humic acid levels in soils can be depleted by wind and water erosion and by water leaching, so their levels must be replenished, and the fertility of poor soils can be improved by the addition of humic acids. Since humic acids are formed in senescent plant matter, it is important that plant trash from harvested crops is returned to the soil. Modern agricultural practices often ignore this, because crops are planted quickly after each other and the remains of the previous crop are disposed of or burnt. Burning should be avoided and only carried out if it is essential for disease protection.

To increase the humic acid levels in soils (especially in poor soils), not only must plant matter be recycled, but the addition of humic acid-rich materials may be required. Humic acid-rich materials include composts, mulch, peat, and lignite coals. Commercial soluble potassium humate products provide little long-term benefit and are relatively expensive, so they are not a good proposition. There are already excellent processes with suitable equipment to provide composts and mulches on farms, but this procedure should become much more common in modern agriculture, just as it was in past eras. In some developing countries, their huge supplies of lignite coals are being used in agriculture as a rich source of humic acids, but in developed countries, electricity production takes precedence. Although lignite coals are a plentiful source of humic acids, there could be a high cost of transport, which makes crop recycling and composting or mulching a more attractive alternative.

Acknowledgments: The fluorometer was accessed at the Chemistry Department of the University of Queensland, Brisbane, Australia.

Conflicts of Interest: The author declares no conflict of interest.

\section{References}

1. BioStim Certificate in Sustainable Agriculture. Available online: http://www.biostim.com.au/biostimcertificate-in-sustainable-agriculture.html (accessed on 14 July 2016).

2. Susic, M.; Boto, K.; Isdale, P. Fluorescent humic acid bands in coral skeletons originate from terrestrial runoff. Mar. Chem. 1991, 33, 91-104. [CrossRef]

3. Susic, M.; Isdale, P. Hydraulic and Environmental Modelling of Coastal, Estuarine and River Waters; Falconer, R.A., Goodwin, P., Matthews, R.G.S., Eds.; Gower Technical: Aldershot, UK, 1989; pp. 588-597.

4. Achard, F.K. Chemische untersuchung des torfs. Crell's Chem. Ann. 1786, 2, 391-403.

5. Humic Acid. More than Two Centuries of Humic Acid Research—Why So Long? Available online: https: / /humicacid.wordpress.com/a-history-of-humic-acid-research (accessed on 14 July 2016).

6. Farmer, V.C.; Pisaniello, D.L. Against an aromatic structure for soil fulvic acid. Nature 1985, 313, 474-475. [CrossRef]

7. Vauquelin, C. Sur une maladie des arbres qui attaque spécialement l'orme et qui est analogue à un ulcère. Ann. Chim. 1797, 21, 39-47.

8. Frimmel, F.H.; Bauer, H. Influence of photochemical reactions on the optical properties of aquatic humic substances gained from fall leaves. Sci. Total Environ. 1987, 62, 139-148. [CrossRef]

9. Susic, M.; Boto, K.G. High-performance liquid chromatographic determination of humic acid in environmental samples at the nanogram level using fluorescence detection. J. Chromatogr. 1989, 482, 175-187. [CrossRef]

10. Davies, G.; Fataftah, A.; Ghabbour, E.A.; Jansen, S.A.; Radwan, A.; Raffauf, R.F. Isolation of humic acid from the terrestrial plant Brugmansia sanguinea. Sci. Total Environ. 1997, 201, 79-87. [CrossRef] 
11. Davies, G.; Fataftah, A.; Radwin, A.; Willey, R.J.; Ghabbour, E.A.; Jansen, S.A. The Role of Humic Substances in the Ecosystems and in Environmental Protection; Drozd, J., Gonet, S.S., Senesi, N., Weber, J., Eds.; Polish Society of Humic Sustances: Wroclaw, Poland, August 1997; pp. 567-572.

12. Adani, F.; Spagnol, M.; Genevini, P. Biochemical origin and refractory properties of humic acid extracted from the maize plant. Biogeochemistry 2006, 78, 85-96. [CrossRef]

13. Nebbioso, A.; Piccolo, A. Functions of Natural Organic Matter in Changing Environment; Xu, J., Wu, J., He, Y., Eds.; Zhejiang University Press: Hangzhou, China; Springer: Dordrecht, The Netherlands, 2013; pp. 89-94.

14. Tan, K.H. Humic Matter in Soil and the Environment: Principles and Controversies, 2nd ed.; CRC Press: Boca Raton, FL, USA, 2014; pp. 236-243.

15. Humic Acid. Structure and Origin of Humic Acids and Their Relationship to Kerogen, Bitumen, Petroleum and Coal. Available online: https:/ / humicacid.wordpress.com/structure-and-origin-of-humic-acids-andtheir-relationship-to-kerogen-bitumen-petroleum-and-coal/ (accessed on 14 July 2016).

16. Susic, M. Girl or Boy? New Fulvic Acids Research. Available online: https:/ /humicacid.wordpress.com/ girl-or-boy-new-fulvic-acids-research/ (accessed on 14 July 2016).

(C) 2016 by the author; licensee MDPI, Basel, Switzerland. This article is an open access article distributed under the terms and conditions of the Creative Commons Attribution (CC-BY) license (http://creativecommons.org/licenses/by/4.0/). 